\title{
Sentimento de mulheres mastectomizadas acerca da autoimagem e alterações na vida diária
}

\author{
Feelings of mastectomy women about self image and changes in daily life
}

Elenir de Araújo Lago a, Nathalia Kelly de Sousa Andradeb, Inez Sampaio Neryc, Fernanda Valéria Silva Dantas Avelino ${ }^{d}$

a Enfermeira. Especialista em Vigilância em Saúde. Universidade Federal do Piauí - UFPI, Teresina, PI, Brasil.

b Enfermeira. Graduada pela Universidade Federal do Piauí - UFPI, Teresina, PI, Brasil.

c Enfermeira. Doutora em Enfermagem, Professora Associada IV do Curso de Enfermagem-bacharelado da UFPI, membro efetivo dos Programas de Pós-Graduação em Enfermagem e Políticas Públicas (strictu senso), Teresina, PI, Brasil.

d Enfermeira. Doutora em Enfermagem. Professora Ádjunto do Departamento de Enfermagem do Centro de Ciências da Saúde, Universidade Federal de do Piauí, Teresina, PI, Brasil.

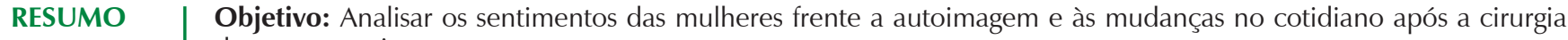
de mastectomia.

Materiais e Métodos: Estudo realizado no ambulatório do hospital referência em Teresina-PI, trata-se de uma pesquisa qualitativa, com aplicação de roteiro semiestruturado em dez mulheres mastectomizadas em tratamento oncológico no período entre novembro de 2010 e janeiro de 2011. As entrevistas foram gravadas e transcritas na íntegra e optou-se pela análise temática segundo Bardin.

Resultados: O perfil levantado foi de mulheres com idade acima de 40 anos, predominantemente aposentadas, do lar, católicas e casadas. A vivência pós-mastectomia está associada à baixa estima, não sentir-se mulher e ausência do significado de vida. Referiram ainda o abandono ou a redução de suas atividades domésticas ou laborais, impostas pelas limitações da mastectomia.

Conclusão: A mastectomia gera um misto de sentimentos e altera a imagem corporal, autoestima, relações sociais e cotidianas.

PALAVRAS-ChaVE: Mastectomia. Emoções. Imagem corporal. Enfermagem.

Objective: To analyze the feelings of women facing the self-image and changes in everyday after mastectomy surgery.

Materials and Methods: The study was conducted in the outpatient referral hospital in Teresina-PI. It is a qualitative research, with application of semi-structured guidebook. Ten women who had had mastectomy for cancer treatment in the period between November 2010 and January 2011 were included. The interviews were recorded and transcribed in full and we opted for thematic analysis according to Bardin.

Results: The women included were aged over 40 years, mostly retired, housewifes, catholic and married. Post-mastectomy experience was associated with low self-esteem; not feelling like a woman and absence of meaning of life. Also, subjects mentioned the abandonment or reduction of their domestic or work activities, imposed by the limitations of the mastectomy.

Conclusion: Mastectomy generates mixed feelings and alters the body image, self-esteem, social and everyday relationships.

KEYWORDS: Mastectomy. Emotions. Body image. Nursing. 


\section{INTRODUÇÃO}

O câncer representa mais de 100 doenças, incluindo tumores malignos de diferentes localizações. O câncer de mama é o segundo tipo mais frequente no mundo, o mais comum entre as mulheres e apresenta altas taxas de mortalidade ${ }^{1}$.

A precisão diagnóstica, a qualidade do preenchimento das declarações de óbitos e o aumento da esperança de vida são responsáveis pelo crescimento das taxas de incidência e da mortalidade. A etiologia do câncer de mama envolve fatores de risco associados à vida reprodutiva da mulher, exposição à radiação ionizante, características genéticas, maus hábitos alimentares, fatores hormonais, antecedente familiar e influência ambiental ${ }^{2}$.

$\mathrm{Na}$ fase em que seu diagnóstico é confirmado, sua vida começa a sofrer uma série de outras influências como medo da morte, as questões e mitos que envolvem o câncer, a ansiedade do momento que antecede a cirurgia, o pós-operatório, o se perceber mastectomizada e tantos outros ${ }^{3,4}$.

A doença pode ser avaliada conforme a extensão do tumor, as suas características e a classificação do câncer, a partir disso escolhe-se o tratamento mais adequado, tais como: a quimioterapia, a radioterapia, a terapia hormonal e a cirurgia, seja individual ou concomitante ${ }^{5}$.

A cirurgia de mastectomia foi descrita inicialmente pelo médico-cirurgião Hasteld, esta técnica consiste na retirada total da mama afetada pelo câncer e, por ser considerada um procedimento cirúrgico extremamente agressivo, atualmente vem sendo substituída por outras cirurgias que preservam mais a mama, como a quadractomia e lumpectomia ${ }^{6}$.

Por ser radical, a mastectomia traz uma gama de mudanças na vida dessa mulher, provoca alterações em sua autoimagem, no relacionamento com o próprio corpo, na sexualidade e nas relações sociais, pois as mulheres sentemse castradas e mutiladas sexualmente, vendo-se distante do ideal, e julgando-se incapazes de satisfazer sexualmente seus parceiros e consequentemente provocando mudanças no autoconceito ${ }^{3,4,7}$.

A reconstrução da mama é uma alternativa para reabilitação e eufêmica o impacto psicológico sofrido pelas mulheres mastectomizadas ${ }^{8}$. Nessa conjuntura, a enfermagem deve compreender os sentimentos das mulheres mastectomizadas, a fim de diagnosticar as principais necessidades e realizar um planejamento de enfermagem mais coerente na assistência a essas.

Neste sentido, o estudo teve como objetivos descrever e analisar os sentimentos das mulheres em tratamento oncológico, em um Hospital filantrópico de Teresina-PI, frente a autoimagem e às mudanças no cotidiano após a cirurgia de mastectomia.

\section{MATERIAIS E MÉTODOS}

A pesquisa é de abordagem qualitativa, a qual permite compreensão das relações, representações, crenças, percepções e opiniões, produtos de interpretação que os humanos fazem a respeito de como vivem, constroem artefatos e a si mesmos, sentem e pensam ${ }^{9}$.

Trata-se de um recorte do estudo intitulado "Os sentimentos vivenciados por mulheres mastectomizadas em Teresina (PI)" e teve como objetivo descrever os sentimentos das mulheres mastectomizadas em hospital de referência oncológica e discutir esses sentimentos e a assistência de enfermagem relatada pelas mulheres durante o seu tratamento.

A amostra foi estabelecida conforme saturação de falas, dessa forma, a pesquisa teve como sujeito dez mulheres e sua participação teve como critérios: vivência de ser mastectomizada, encontrar-se em acompanhamento de médico oncologista e possuir discernimento suficiente para aceitar livremente a sua participação na pesquisa. O campo selecionado para o estudo foi o setor ginecológico do ambulatório de hospital filantrópico de Teresina-PI, referência no tratamento do câncer.

A coleta de dados ocorreu no período de novembro de 2010 a janeiro de 2011 utilizando como técnica o roteiro semiestruturado. As entrevistas ocorreram de forma espontânea, permitindo a participante relatar suas experiências. Foram gravadas e transcritas na íntegra, identificadas pela letra " $\mathrm{D}$ " acompanhada do dígito numérico 1, 2 e assim por diante. À medida que as falas ficaram repetitivas, houve a finalização da coleta.

Optou-se pela análise de conteúdo por meio de categorias temática, dispondo os relatos conforme o agrupamento de falas comuns, obedecendo as três etapas: pré-análise, definida como fase de organização dos depoimentos por meio da leitura flutuante e elaboração de indicadores que fundamentam a interpretação; exploração do material, com codificação das unidades de registro; e tratamento dos resultados e interpretação, que é a fase que há a classificação dos elementos segundo semelhanças, para posterior reagrupamento a partir do qual elaborou-se as categorias temáticas ${ }^{10}$.

Obteve-se a aprovação do Comitê de Ética em Pesquisa da Universidade Federal do Piauí (CAAE-0273.0.045.000-10) e do Centro de Ensino e Pesquisa do hospital em questão, assim como a permissão das entrevistadas através da assinatura do termo de consentimento livre e esclarecido, conforme a resolução 466/2012 do Conselho Nacional de Pesquisa. 


\section{RESULTADOS E DISCUSSÃO}

Os resultados compreenderam as mulheres mastectomizadas dentre as quais a $90 \%$ apresentavam idade acima de 40 anos (9), 30\% eram casadas (3), 30\% eram solteiras (3), 50\% eram católicas (5). Em relação à ocupação observou-se que 30\% eram aposentadas (3) e 30\% eram donas de casa (3).

Dos relatos das mulheres emergiram as seguintes categorias: Sentimentos relacionados à autoimagem pósmastectomia e alterações vivenciadas na rotina e trabalho após cirurgia reparadora.

\section{Sentimentos relacionados à autoimagem pós-mastectomia}

A vivência das mulheres pós-mastectomia mesmo com a reconstrução mamária, traz sofrimento e conflitos embora tenha possibilitado crescimento emocional e a capacidade de resiliência. Eis os relatos:

\begin{abstract}
"Sentimento de perda... sentimento que nada vai dá certo $[. .$.$] que deixou de ser mulher.. que a vida não$ tem mais sentido para você [...]." (D 1)

"[...] Eu logo que fiz a cirurgia de retirada total da mama, já fui diretamente para o cirurgião plástico, fiz tudo na mesma sala, já saí com a plástica, mas não é a mesma coisa... Nunca vai voltar ao que era [...]." (D 2)
\end{abstract}

O sofrimento diante da perda da mama, associada a baixa-estima, o não sentir-se mulher e a ausência de significado na vida em consequência da mutilação, está presente nos depoimentos referidos.

Isso porque o seio é o órgão do corpo feminino símbolo de fertilidade e saúde durante todas as etapas da sua vida, e está relacionado à questão da feminilidade, um objeto central de desejo e satisfação sexual, e ao adquirir uma doença localizada neste objeto que destroem todas as possibilidades de simbolização da mulher enquanto ser feminino termina por questionar a sua identidade e sua capacidade de amamentação e de sensualidade ${ }^{11}$.

Depois da cirurgia, a mulher se sente incompleta e marginalizada, pois a ausência do órgão é algo devastador. Muitas aceitam a perda do seio por ser o único modo para a cura, enquanto para outras, essa situação é traumática. Nesse momento, os acontecimentos ocorridos na sua vida, influenciam positiva ou negativamente na aceitação da nova imagem $^{3}$.

A reconstrução mamária pode acontecer logo após a cirurgia ou tardiamente, contudo quanto mais precoce, melhor os benefícios. Embora possam surgir complicações associadas a outro procedimento e o impacto psicológico não seja totalmente restabelecido em decorrência da mastectomia, as sequelas emocionais e físicas podem ser minimizadas pela cirurgia reparadora ${ }^{12}$.

Em estudo a maioria das mulheres que realizou a reconstrução mamária obteve uma melhora na qualidade de vida, puderam retornar as atividades habituais, resgatar a sua imagem corporal, o sentimento de feminilidade, a afetividade e autoestima, não precisando utilizar artifícios como pedaços (retalhos) de tecidos ${ }^{12}$.

\section{Alterações vivenciadas na rotina e trabalho após cirurgia reparadora}

No que refere as alterações vivenciadas na rotina e trabalho após cirurgia reparadora as mulheres referem ter abandonado ou diminuído suas atividades, em decorrência das limitações da mastectomia como, por exemplo, não poder carregar peso e fazer trabalho com demanda de força por sentirem dor, além de outras como mudanças na alimentação.

Um estudo ${ }^{13}$ afirma que de dez mulheres, quatro (40\%) deixaram de trabalhar fora da residência em consequência da cirurgia, mas as entrevistadas revelaram que deixaram de fazer algumas tarefas de casa após a mastectomia, porém não afirmaram que desistiram de empregos fora de casa devido a doença ou a cirurgia.

Com os depoimentos é explícito o incômodo sentido por elas ao ter de depender de outros para realizar a rotina diária anteriormente desempenhada por elas próprias.

"Meus médicos me empurravam para uma licença, somente um me disse vá, trabalhe." (D 2)

“Deixar de fazer deixei tudo, até minha casa tô longe uns dois meses, tô na casa alheia, ruim, mas quando a gente pensa no ruim também pensa no bem, em ficar boa, excluir." (D 8)

"O que mudou é que não fiquei trabalhando bem como trabalhava. Fiquei mais de um ano sem trabaIhar em casa, na insistência de não pegar peso, não lavar roupa, não passar pano em casa [...]Eu sinto fraqueza nos nervos, eu passei susto pra dormir. (vergonha) [...] Eu quando pego qualquer peso chambeia os nervos, fica dolorida, mas isso não impata em fazer qualquer coisa, e logo porque não fico pegando peso." (D 9).

"Minha vida mudou que eu me senti dolorida na operação, tem dia que eu me sinto dolorida na operação. Eu trabalhava de roça e hoje não trabalho mais" (D 10). 
As depoentes não enfocaram os sintomas sentidos após a mastectomia, e sim a mudança na rotina diária. Elas referem principalmente a dor e a fraqueza. Num estudo ${ }^{14}$ são citados a fadiga, náusea e vômito, dor, dispneia, insônia, perda de apetite, constipação e diarreia.

Em relação a alteração da rotina, as depoentes evidenciaram que por causa do tratamento as mulheres que exerciam trabalho remunerado se mostraram preocupadas por terem que se ausentar de suas casas e pelas limitações no trabalho doméstico, pois ao deixar ou diminuir as tarefas habituais havia um sentimento de inutilidade. Isso demandou reflexões e conscientização das limitações diante da nova situação apresentada por estas mulheres a fim de prevenir complicações decorrentes da mastectomia ${ }^{15}$. As dificuldades em retornar para a vida profissional, social, familiar e sexual são causadas, em geral, pela dificuldade em lidar com o próprio corpo, no período pós-operatório de mastectomia ${ }^{5}$.

Essa preocupação também foi apresentada no estudo ${ }^{14}$, entre as pacientes mais jovens, pois a abdicação do seu trabalho acarretava maiores dificuldades financeiras. Atualmente as mulheres contribuem mais no ambiente familiar, muitas chefiam o lar e a ausência do seu salário aumenta a vulnerabilidade do lar.

Além das limitações físicas, as mulheres também passaram a enfrentar as limitações sociais, como a mudança de papéis, ou abrir mão das atividades rotineiras, tais como o trabalho, o cuidado com os filhos e a casa ${ }^{3}$. Nessa nova realidade, é necessário a readaptação das atividades rotineiras, e estímulo para que estas não desistam e busquem saídas para sua nova condição, por isso é importante a ajuda de uma equipe de saúde qualificada para atender as necessidades de saúde, em especial de enfermagem.

\section{CONSIDERAÇÕES FINAIS}

Após a comprovação do diagnóstico da neoplasia na mama as mulheres vivenciam momento de imensa angústia, sofrimento e ansiedade, principalmente pelo fato de essa ser uma doença estigmatizante na nossa sociedade. Além disso, durante o tratamento elas vivenciam perdas físicas e financeiras, e sintomas adversos, tais como: sentimento de perda, depressão, autoimagem prejudicada com diminuição da autoestima e da libido sexual, medo da morte, sendo necessárias constantes adaptações às mudanças físicas, psicológicas, sociais, familiares e emocionais ocorridas.

Houve mudanças significativas na rotina das mulheres mastectomizadas, já que tiveram de modificar ou se ausentar das atividades laborais e domésticas, necessitando readaptarse a nova condição imposta. Por isso, a importância do presente estudo, já que imergiu no íntimo das mulheres mastectomizadas e obteve-se os relatos sobre os sentimentos dessas com relação a autoestima e as mudanças vivenciadas por elas no ambiente doméstico e laboral, podendo dessa maneira, o cuidado deve ser direcionado e prestar as orientações específicas conforme as principais necessidades levantadas.

\section{REFERÊNCIAS}

1. Brasil. Instituto Nacional de Câncer José Alencar Gomes da Silva (INCA). Estimativa 2014: incidência de câncer no Brasil. Rio de Janeiro (RJ): INCA; 2014.

2. Brasil. Instituto Nacional de Câncer José Alencar Gomes da Silva (INCA). Estimativa 2012: incidência de câncer no Brasil. Rio de Janeiro (RJ): INCA; 2011. [capturado 2012 jan. 8]. Disponível em: <http://www.inca.gov.br/estimativa/2012>.

3. Machado DL. Sendo companheiro de uma mulher mastectomizada: buscando ferramentas para a adaptação [dissertação]. Rio de Janeiro (RJ): Universidade do Estado do Rio de Janeiro, Enfermagem; 2006.

4. Fabbro MEC, Montrone AVG, Santos S. Percepções, conhecimentos e vivencias de mulheres com câncer de mama. Rev Enferm UERJ. 2008;16(4):532-7.

5. Almeida RA. Impacto da mastectomia na vida da mulher. Revista SBPH. 2006;9(2):99-113.

6. Boff AR. Repercussões associadas à terapêutica cirúrgica de mulheres com câncer de mama [dissertação]. Dissertação não-publicada. São Paulo (SP): Universidade de São Paulo; 1999.

7. Conceição LL, Lopes RLM. O cotidiano de mulheres mastectomizadas: do diagnótico à quimioterapia. Rev Enferm UERJ. 2008; 16(1):26-31.

8. Duarte TP, Andrade AN. Enfrentando a mastectomia: análise dos relatos de mulheres mastectomizadas sobre questões ligadas à sexualidade. Estud Psicol (Natal) [online]. 2003;8(1):155-63 [capturado 2015 fev. 25]. http://dx.doi.org/10.1590/S1413294X2003000100017

9. Minayo MC. O desafio do conhecimento: pesquisa qualitativa em saúde. São Paulo: Hucitec; 2010.

10. Bardin L. Análise de conteúdo. São Paulo: Edições 70; 2011.

11. Vieira CP, Lopes MHBM, Shimo AKK. Sentimentos e experiências na vida das mulheres com câncer de mama. Rev Esc Enferm USP 2007;41(2):311-6. http://dx.doi.org/10.1590/S008062342007000200020

12. Azevedo RF, Lopes RLM. Revisando as contribuições da reconstrução mamária para mulheres após a mastectomia por câncer. Rev Enferm UERJ. 2010;18(2):298-303.

13. Araújo IMA, Fernandes AFC. O significado do diagnostico do câncer de mama para a mulher. Esc Anna Nery Rev Enferm. 2008;12(4):66471. http://dx.doi.org/10.1590/S1414-81452008000400009

14. Furlan VLA, Neto MS, Abla LEF, Oliveira CJR, Lima AC, Ruiz BFO, Ferreira LM. Qualidade de vida e autoestima de pacientes mastectomizadas submetidas ou não a reconstrução de mama. Rev Bras Cir Plást. 2013;28(2):264-9. http://dx.doi.org/10.1590/S198351752013000200016

15. Oliveira MS, Souza AMA, Fernandes AFC. Grupo apoyo/soporte: espacio de rehabilitación para mujeres mastectomizadas. Rev Eletr Enf. 2008;10(3):816-22. [capturado 2012 fev. 12] Disponível em: <http://www.fen.ufg.br/revista/v10/n3/v10n3a27.htm>. 